\title{
ESTIMASI SELEKTIVITAS ALAT TANGKAP PANCING DI SUNGAI NILO KECAMATAN MUARA SIAU KABUPATEN MERANGIN PROVINSI JAMBI
}

\author{
Roni Asmala Dewi ${ }^{1}$ Muhammad Natsir Kholis ${ }^{2^{*}}$ Syafrialdi $^{2}$ \\ ${ }^{I}$ Mahasiswa Jurusan Pemanfaatan Sumberdaya Perikanan Fakultas Perikanan, \\ Universitas Muara Bungo-Jambi \\ ${ }^{2}$ Staf Pengajar Jurusan Pemanfaatan Sumberdaya Perikanan Fakultas Perikanan, \\ Universitas Muara Bungo-Jambi \\ *Email: kholis2336@gmail.com
}

\begin{abstract}
ABSTRAK
Selektivitas merupakan salah satu indikator alat penangkapan ikan ramah lingkungan. Tujuan penelitian ini yaitu untuk mengestimasi selektivitas alat tangkap pancing yang dioperasikan di sungai nilo. Metode yang digunakan dalam penelitian ini adalah metode survei. Data diambil dengan cara observasi langsung kelapangan menggunakan teknik eksperimental fishing. Semua ikan yang tertangkap dianalisis dengan menggunakan formula selektivitas Sparre and Venema (1999). Hasil penelitian menunjukan bahwa pancing yang dioperasikan di sungai nilo memiliki estimasi nilai selektivitas terhadap ikan ukuran mata pancing no. 1 pada panjang $16,537 \mathrm{~cm}$ dan ukuran mata pancing no. 3 pada panjang 20,691 cm. Panjang ikan hasil tangkapan yang memiliki panjang terluar di bawah dan diatas nilai perkiraan selektivitas kemungkinan tidak akan memakan umpan karena size ukuran mata pancing lebih besar dan lebih kecil dari bukaan mulut ikan.
\end{abstract}

Kata Kunci : Estimasi Selektivitas, Jambi, Muara Siau, Pancing, Sungai Nilo,

\begin{abstract}
Selectivity is an indicator of environmentally friendly fishing gear. The purpose of this study is to estimate the selectivity of fishing gear operated in the Nilo river. The data were taken by direct observation in the field using experimental fishing techniques. All the fish caught were analyzed using the selectivity formula Sparre and Venema (1999). The results showed that the fishing rods that are operated in the Nilo river have an estimated value of the selectivity of the fish hook size no. 1 at a length of $16,537 \mathrm{~cm}$ and the size of the hook no. 3 at a length of $20.691 \mathrm{~cm}$. The length of the fish caught that has the outer length below and above the estimated selectivity value is unlikely to eat the bait because the hook size is bigger and smaller than the fish's mouth.
\end{abstract}

Keywords : Selectivity Estimation, Jambi, Muara Siau, Fishing rod, Nilo river 


\section{PENDAHULUAN}

\section{Latar Belakang}

Sungai Nilo merupakan sungai yang terdapat di Kecamatan Muara Siau Kabupaten Merangin yang melintasi pemukiman penduduk, persawahan dan areal perkebunan yang memiliki panjang $55,2 \mathrm{~km}$ dan lebar permukaan $59 \mathrm{~m}$ dengan kedalaman $4 \mathrm{~m}$. Sungai Nilo biasa dimanfaatkan masyarakat untuk keperluan sehari-hari diantaranya mandi dan mencuci, selain itu juga dimanfaatkan masyarakat untuk menangkap ikan. Aktivitas penangkapan di perairan ini sangat berkembang, menggunakan macam jenis alat tangkap, metode penangkapan dan hasil tangkapan yang bervariasi (BLH Jambi, 2015)

Salah satu alat penangkapan ikan yang digunakan masyarakat di sungai Nilo adalah pancing. Masyarakat di Sungai Nilo menjadi nelayan untuk mendapatkan penghasilan tam-bahan, dan ada juga sebagian masyarakat hanya mencari hiburan untuk menangkap ikan. Pancing yang sering digunakan oleh nelayan di sungai nilo pada umumnya adalah pancing dengan memakai joran dari batang bambu dan kayu, namun ada juga yang sudah menggunakan pancing yang dibeli di pasaran, dengan mata pancing yang sering digunakan adalah mata pancing no. 1,2 dan 3 .

Prinsip penangkapan pancing sangat sederhana yakni hanya meletakkan umpan pada mata pancing, lalu pancing diberi tali. Setelah umpan di makan ikan maka mata pancing juga akan termakan oleh ikan dan dengan tali, pemancing menarik ikan ke atas kapal atau ke darat (Ayodhyoa, 1981).

Selektivitas merupakan salah satu indikator alat penangkapan ikan ramah lingkungan. Setiap alat penangkapan ikan memiliki selektivitas yang berbeda. Selektivitas pancing dapat diukur dari besar kecilnya ukuran mata pancing (hook) yang digunakan. Mata pancing (hook) merupakan bagian yang paling penting dari pancing. Mata pancing kecil ada kemungkinan menangkap ikan yang lebih besar, tetapi ukuran mata pancing besar berpeluang kecil menangkap ikan ukuran kecil (Nugroho, 2002).

Mata pancing mempunyai bentuk dan ukuran yang berbeda-beda dan sangat berpengaruh terhadap ukuran ikan sasaran. Mata pancing yang dipasang disesuaikan dengan lebar bukaan mulut ikan. Ukuran bukaan mulut ikan memudahkan ikan memakan atau menelan mata pancing dan memudahkan mata pancing tertelan atau tersangkut di dalam mulut ikan, sehingga peluang tertangkapnya ikan lebih besar (Kurnia et al., 2015).

Penelitian selektivitas dan efesiensi pada pancing jarang dilakukan, tetapi beberapa hasil penelitian seperti penelitian Hutabessy et al., (2015) menunjukkan bahwa panjang tertahan maksimum mata kail no. 7 lebih rendah dibandingkan mata kail no. 8 yang berukuran lebih kecil dengan distribusi panjang ikan yang tumpang tindih. Sehingga efisiensi penangkapan dari kedua mata kail ini belum dapat dibedakan. Sedangkan hasil penelitian Amirulloh et al., (2014), menyatakan bahwa hasil tangkapan mata pancing no. 7 lebih efektif dan efisien dari mata pancing no. 8 dan mata pancing no. 9 . Hal ini mendorong perlu dilakukannya penelitian mengenai estimasi selektivitas ukuran mata pancing no. 
1 dan 3 dalam menangkap hasil tangkapan. Penelitian ini bertujuan untuk mengestimasi selektivitas alat

\section{METODE PENELITIAN Waktu dan Tempat}

Penelitian ini dilaksanakan pada bulan Mei sampai Juli 2020. Penelitian dilakukan di sungai nilo Kecamatan Muara Siau Kabupaten Merangin Provinsi Jambi. Dengan 3 stasiun penelitian, terdiri dari: stasiun (1) berada pada titik koordinat $02^{0} 14^{\prime} 11,01$ 'LS dan $102^{0} 1{ }^{\prime} 32,28^{\prime \prime}$ 'BT tangkap pancing di sungai nilo Kecamatan Muara Siau Kabupaten Merangin Provinsi Jambi.

dengan jarak $1 \mathrm{Km}$ dengan stasiun (2) yang berada pada titik koordinat $02^{0} 13$ '51,68" LS dan $102^{0} 1$ '57,72” BT yang berjarak $\pm 660 \mathrm{~m}$ dari stasiun (3) yaitu pada titik koordinat koordinat $02^{0} 144^{\prime} 3,17^{\prime \prime} \mathrm{LS}$ dan $102^{0} 2^{\prime} 16,54^{\prime \prime} \mathrm{BT}$ dan penelitian ini dilaksanakan selama 3 bulan yaitu dari Mei sampai Juli 2020. Peta lokasi penelitian dapat dilihat pada (Gambar 1).
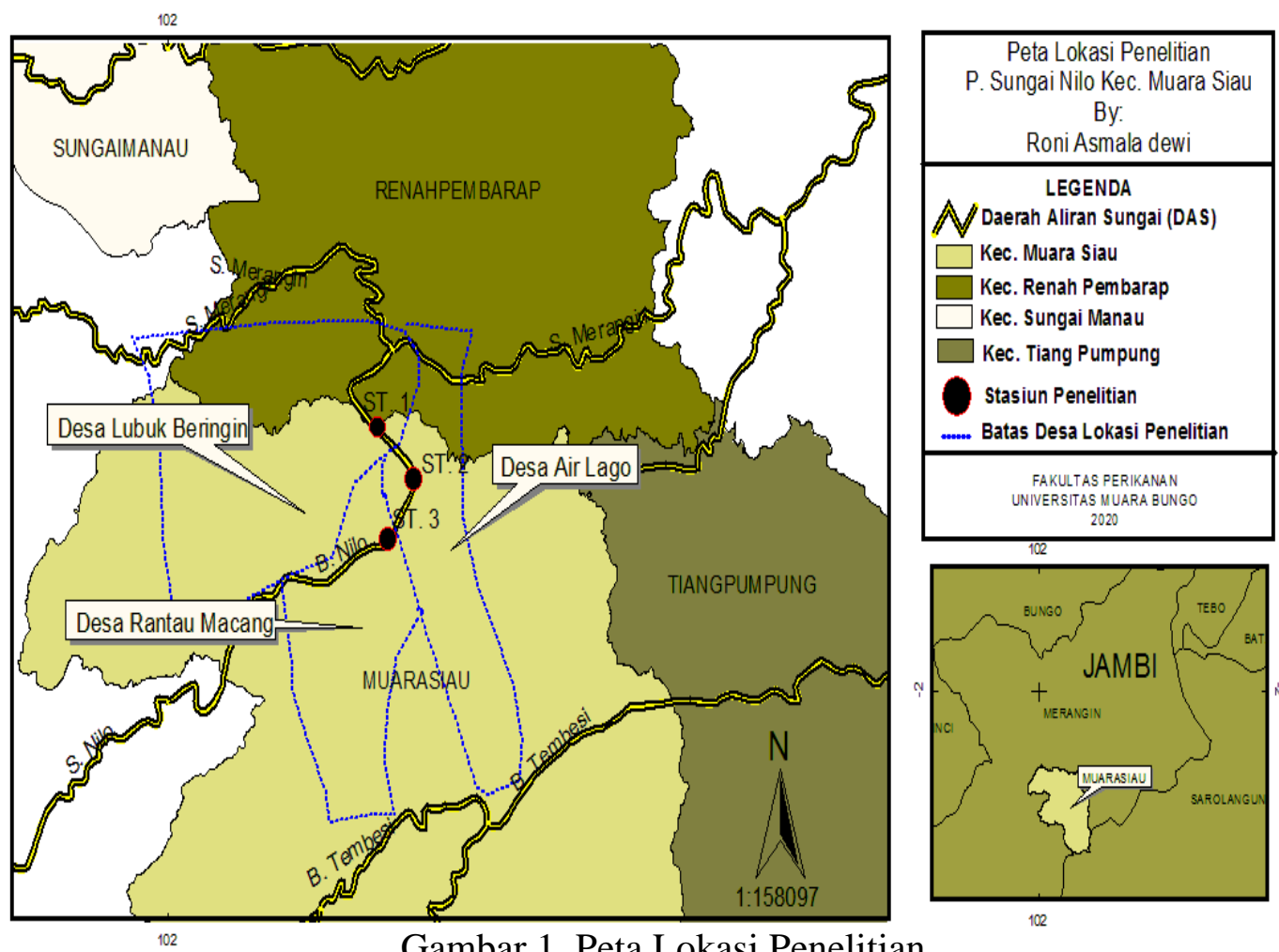

\section{Alat dan Bahan}

Alat yang digunakan pada penelitian ini yaitu: alat tangkap pancing dengan ukuran mata pancing yang berbeda yaitu no. 1 dan no. 3 (Gambar 2), penggaris, meteran, kamera digital, alat tulis, jangka sorong dan timbangan elektrik. Sedangkan bahan yang digunakan yaitu umpan dan hasil tangkapan ikan. 


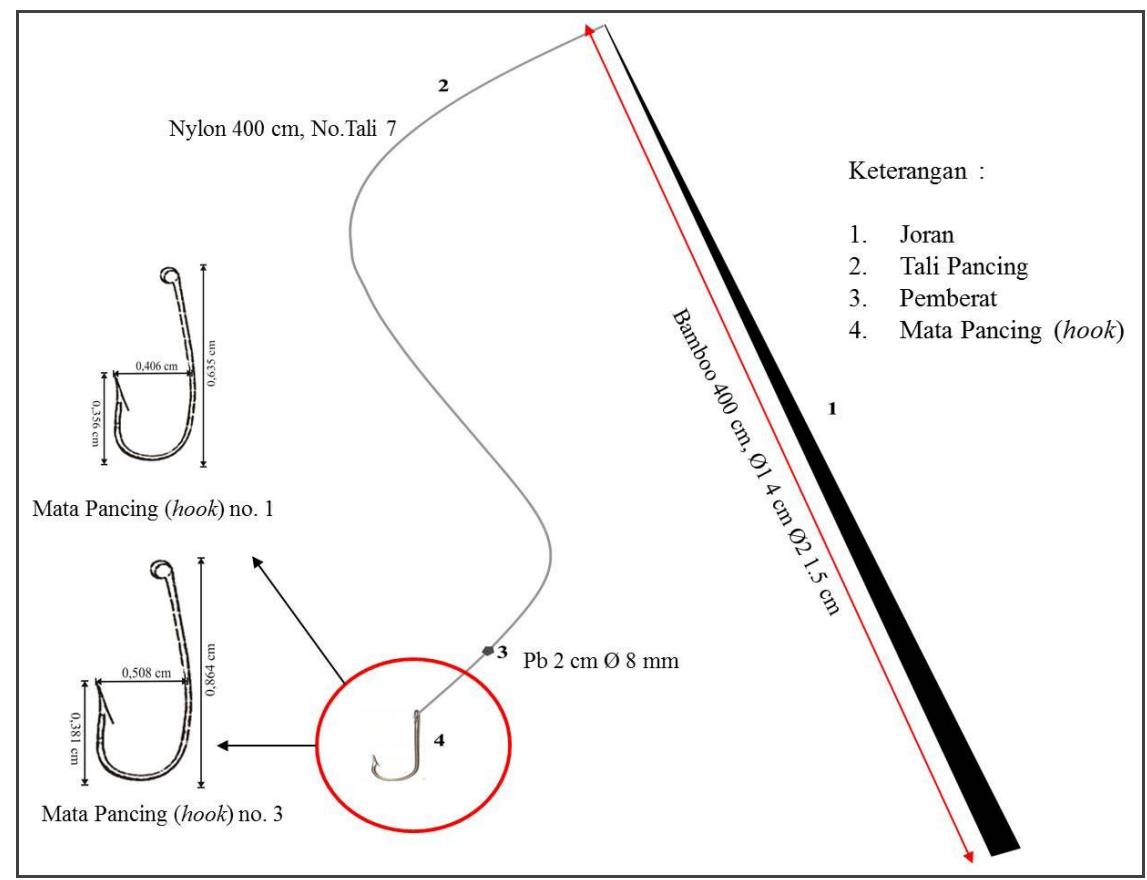

Gambar 2. Konstruksi Pancing

\section{Sumber Data}

Metode yang digunakan pada penelitian ini yaitu metode survei. Data yang digunakan terdiri dari data primer dan sekunder. Data primer diambil dengan cara observasi langsung kelapangan menggunakan teknik ekperimental fishing. Sedangkan data sekunder diambil dengan cara menelaah laporan atau tulisan yang relevan dari Dinas Perikanan, BPS dan Kecamatan.

\section{Teknik Pengumpulan Data}

Pengumpulan data dilakukan dengan operasi penangkapan ikan, terdiri dari persiapan umpan, persiapan alat tangkap pancing dan pemancingan. Tahap persiapan umpan dilakukan pada pagi hari sebelum operasi penangkapan. Persiapan alat tangkap meliputi perakitan, pengecekan dan menyusun pancing dalam satu wadah agar mudah dibawa. Pancing yang digunakan sebanyak 2 buah untuk setiap perlakuanya dan menggunakan karet warna untuk menandai setiap perlakuanya. Karet merah untuk mata pancing no. 1 dan karet hijau untuk mata pancing mata pancing no. 3 . Setelah persiapan selesai semua, kemudian menuju fishing ground untuk melakukan penangkapan ikan.

Setelah sampai di tempat fishing ground dilakukan pemasangan umpan pada mata pancing, kemudian pancing dilemparkan kedalam sungai, pemasangan pancing diatur dengan jarak $3 \mathrm{~m}$ sampai $4 \mathrm{~m}$ agar pancing tidak saling bersangkutan untuk setiap perlakuan sesuai kondisi perairan. Selain itu juga untuk menyesuaikan dengan lokasi penelitian, karena memiliki kedalaman yang berbeda-beda. Operasi penangkapan atau memancing dilakukan pada lokasi yang telah ditentukan pada Jam $14 .{ }^{00}$ WIB sampai sore jam $17 .{ }^{00}$ WIB yang dilakukan 1 hari dalam seminggu selama 3 bulan.

Setelah setting sudah dilakukan semua pancing tersebut dibiarkan atau direndam dalam perairan \pm 30 menit 
atau sampai ikan tertangkap mata pancing. Setelah 30 menit atau ikan sudah tertangkap pada mata pancing maka dilakukan hauling atau pancing yang sudah operasikan akan diambil. Ikan yang diperoleh kemudian dipisahkan berdasarkan ukuran mata pancing dimana ikan tersebut tertangkap.

Sampel ikan yang tertangkap kemudian diukur panjangnnya menggunakan meteran dengan ketelitian $0,1 \mathrm{~cm}$ dan ditimbang

\section{Analisis Data}

Data penelitian ini dianalisis dengan menggunakan formula selektivitas alat tangkap ikan Spare and Venema (1999); Yusuf (2016); Warsa dan Purnomo (2019).

$$
\mathrm{S}_{\mathrm{L}}=\exp \left[-\frac{(\mathrm{L}-\mathrm{LM})^{2}}{2 \mathrm{~S}^{2}}\right]
$$

Dimana:

$$
\begin{aligned}
\mathrm{SL}= & \text { ikan dengan kisaran panjang } \mathrm{L} \\
& \text { tertangkap pancing }(0<\mathrm{SL} \leq 1) \\
\mathrm{Lm}= & \text { kisaran panjang optimum ikan } \\
& \text { yang tertangkap } \\
\mathrm{S}= & \text { standar deviasi dan distribusi } \\
& \text { normal } \\
& \text { Proses analisis terhadap ikan }
\end{aligned}
$$
yang tertangkap menurut kelompok panjang untuk masing-masing mata pancing sebagai berikut :

1. Menghitung logaritma rasio untuk masing-masing kelompok panjang yang saling tumpang tindih :

$\mathrm{Y}=\ln \left(\frac{\mathrm{Cb}}{\mathrm{Ca}}\right)$

Dimana :

$\mathrm{Y}=$ frekuensi panjang $(\mathrm{cm})$

$\mathrm{Ca}=$ ikan yang tertangkap pada ukuran mata pancing nomor 1 beratnya dengan menggunakan timbangan ketelitian $0,1 \mathrm{~g}$. Data yang dikumpulkan meliputi jenis ikan, panjang dan berat ikan, jumlah jenis ikan, total hasil tangkapan, fishing ground, waktu penangkapan dan kondisi lingkungan. Data jenis ikan yang tertangkap dengan menggunakan pancing selanjutnya diidentifikasi, ditimbang, diukur dan dicatat untuk ditabulasikan dan dianalisis.

$$
\begin{aligned}
\mathrm{Cb}= & \text { ikan yang tertangkap pada } \\
& \begin{array}{l}
\text { ukuran mata pancing } \\
\text { nomor } 3
\end{array}
\end{aligned}
$$

2. Menganalisis regresi terhadap logaritma rasio $(y=\ln (\mathrm{Cb} / \mathrm{Ca})$ terhadap titik tengah interval panjang ikan $(\mathrm{x}=\mathrm{L})$ dan tentukan $\mathrm{a}$ dan $\mathrm{b}$ :

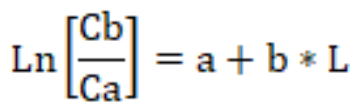

Sehingga dapat ditentukan nilai a dan $b$ dengan cara mengetik rumus pada excel :

- untuk mencari nilai a cukup dengan mengetik rumus = intercept $(\mathrm{y}, \mathrm{x})$

- untuk mencari nilai b cukup mengetik rumus $=$ slope $(y, x)$

3. Tentukan nilai SF, Lma, Lmb, dan s2 dengan menggunakan rumus :

$$
\begin{aligned}
\mathrm{SF}= & \frac{-2 * \mathrm{a}}{\mathrm{b} *(\mathrm{ma}+\mathrm{mb})} \\
\mathrm{SF} & =\text { faktor seleksi } \\
\mathrm{ma} & =\begin{array}{ll}
\text { ukuran mata pancing } \\
\text { nomor } 1
\end{array} \\
\mathrm{mb} & =\begin{array}{l}
\text { ukuran mata pancing } \\
\text { nomor } 3
\end{array} \\
\mathrm{Lma} & =\mathrm{SF} * \mathrm{ma} \\
\mathrm{Lmb} & =\mathrm{SF} * \mathrm{mb}
\end{aligned}
$$




$$
\begin{aligned}
\mathrm{Lma}= & \begin{array}{l}
\text { kisaran panjang optimum } \\
\text { ikan yang tertangkap mata } \\
\text { pancing no. } 1
\end{array} \\
\mathrm{Lmb}= & \text { kisaran panjang optimum } \\
& \text { ikan yang tertangkap mata } \\
& \text { pancing no. } 3
\end{aligned}
$$

Standart Deviasi dapat dicari dengan rumus sebagai berikut:

$$
\begin{aligned}
S^{2} & =\frac{-2 * a(m b-m a)}{b^{2} *(m a+m b)} \\
& =S F * \frac{m b-m a}{b}
\end{aligned}
$$

\section{HASIL DAN PEMBAHASAN}

Komposisi Family Ikan yang Tertangkap

Ikan yang berhasil ditangkap dan teridentifikasi di sungai nilo Kecamatan Muara Siau Kabupaten Merangin Propinsi Jambi menggunakan pancing selama 12 percobaan adalah sebanyak 51 ekor yang terdiri atas 2 family yaitu dari family Bagridae dan Cyprinidae. Untuk lebih jelasnya dapat dilihat pada (Gambar 3).

Berdasarkan (Gambar 3) dapat diketahui bahwa hasil tangkapan yang diperoleh selama penelitian dengan 12 kali percobaan terdiri dari 2 family yaitu Cyprinidae dan Bagridae. Family Cyprinidae merupakan family yang mendominasi

$$
\begin{aligned}
\mathrm{S}^{2} & =\text { standar deviasi } \\
\mathrm{a} & =\text { intersep } \\
\mathrm{b} & =\text { slope }
\end{aligned}
$$

4. Menghitung kurva seleksi dengan memasukkan nilai L ke :

5.

$$
\begin{aligned}
\mathrm{S}_{\mathrm{b}}(\mathrm{L})= & \exp \left[-\frac{(\mathrm{L}-\mathrm{LMb})^{2}}{2 \mathrm{~S}^{2}}\right] \mathrm{S}_{\mathrm{a}}(\mathrm{L}) \\
= & \exp \left[-\frac{(\mathrm{L}-\mathrm{LMa})^{2}}{2 \mathrm{~S}^{2}}\right]
\end{aligned}
$$

yaitu $86 \%$ dan sisanya adalah family Bagridae yaitu $14 \%$. Adapun 2 family tersebut tertangkap pada mata pancing no. 1 dan mata pancing no. 3. Banyaknya ikan yang tertangkap dari family Cyprinidae dikarenakan family ikan ini merupakan family ikan yang sangat umum ditemukan di lingkungan air tawar. Hasil penelitian Jeksen et al., (2018) menunjukan bahwa di sungai tembesi Kabupaten Merangin juga banyak diperolehnya ikan dari family Cyprinidae. Lebih lanjut Kottelat et al., (1993) juga menyatakan bahwa jumlah kekayaan spesies ikan di DAS Batanghari Jambi didominasi oleh family Cyprinidae dengan 77 spesies.

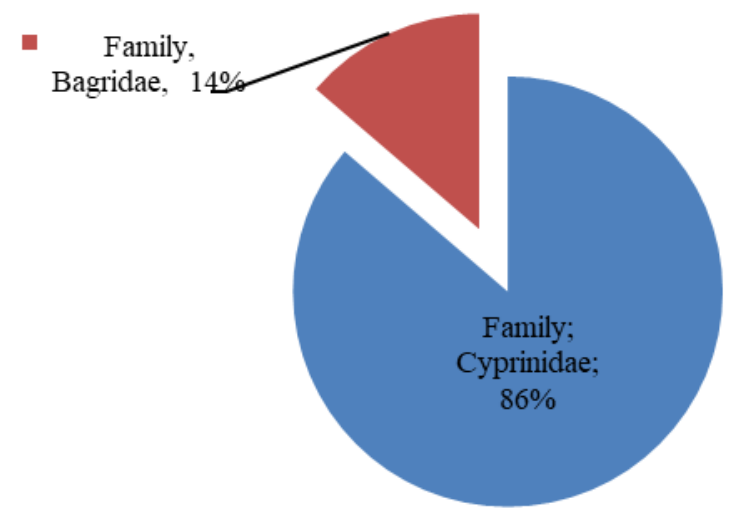

Gambar 3. Komposisi Hasil Tangkapan Berdasarkan Family 
Berdasarkan (Gambar 4) dapat diketahui bahwa jumlah hasil tangkapan utama yang diperoleh selama penelitian sebanyak 9 spesies ikan. Hasil tangkapan didominasi ikan Cato (Barbodes lateristriga) yaitu 29 $\%$, yang tertangkap dengan menggunakan pancing no. 1 sebanyak 14 ekor dan pancing no. 3 sebanyak 1 ekor, dan diikuti ikan Seluang (Rasbora elegans) dengan persentase sebesar $27 \%$ yang hanya tertangkap dengan menggunakan pancing no. 1 . Banyaknya ikan Cato (Barbodes lateristriga) yang tertangkap di sungai nilo dapat disebabkan faktor lingkungan yang merupakan habitatnya ikan Cato (Barbodes lateristriga). Siagian (2009) menyatakan bahwa faktor habitat seperti fisik, dan kimia serta ketersediaan sumber makanan bagi organisme ikan sangat mempengaruhi keberadaan ikan dan dapat mempengaruhi distribusinya dihabitat itu. Menurut Sastrapradja et al., (1981), Barbodes lateristriga adalah species penghuni sungai-sungai kecil, terutama yang jernih dan berbatu-batu di dasarnya, dan sering pula didapati di bawah jeram. Ikan ini memangsa serangga air, cacing krustasea (udang dan ketam), serta bagian-bagian tumbuhan.

\section{Ukuran Panjang, Berat dan Bukaan Mulut Ikan}

Berdasarkan hasil penelitian didapatkan panjang total (Total Lenght), Berat Ikan (g) dan bukaan mulut ikan yang tertangkap pancing di sungai nilo selama 12 kali percobaan. Ukuran mata pancing yang berbeda menangkap ikan dengan kisaran yang berbeda, pada mata pancing no. 1 menangkap ikan dengan panjang total $8-18 \mathrm{~cm}$ dengan kisaran berat 5 - $60 \mathrm{~g}$ dan bukaan mulut $0,228 \mathrm{~cm}-1,143 \mathrm{~cm}$, sedangkan pada mata pancing no. 3 menangkap ikan dengan kisaran panjang total $16-19 \mathrm{~cm}$ dengan kisaran berat $50-60 \mathrm{~cm}$ dan kisaran bukaan mulut 0,559 - 2,083 cm dengan banyak ikan yang tertangkap berbeda-beda. Untuk lebih jelasnya rataan panjang total (TL) ikan, berat ikan $(\mathrm{g})$ dan bukaan mulut $(\mathrm{cm})$ ikan yang tertangkap pancing di sungai nilo dapat dilihat pada (Gambar 5) berikut ini.

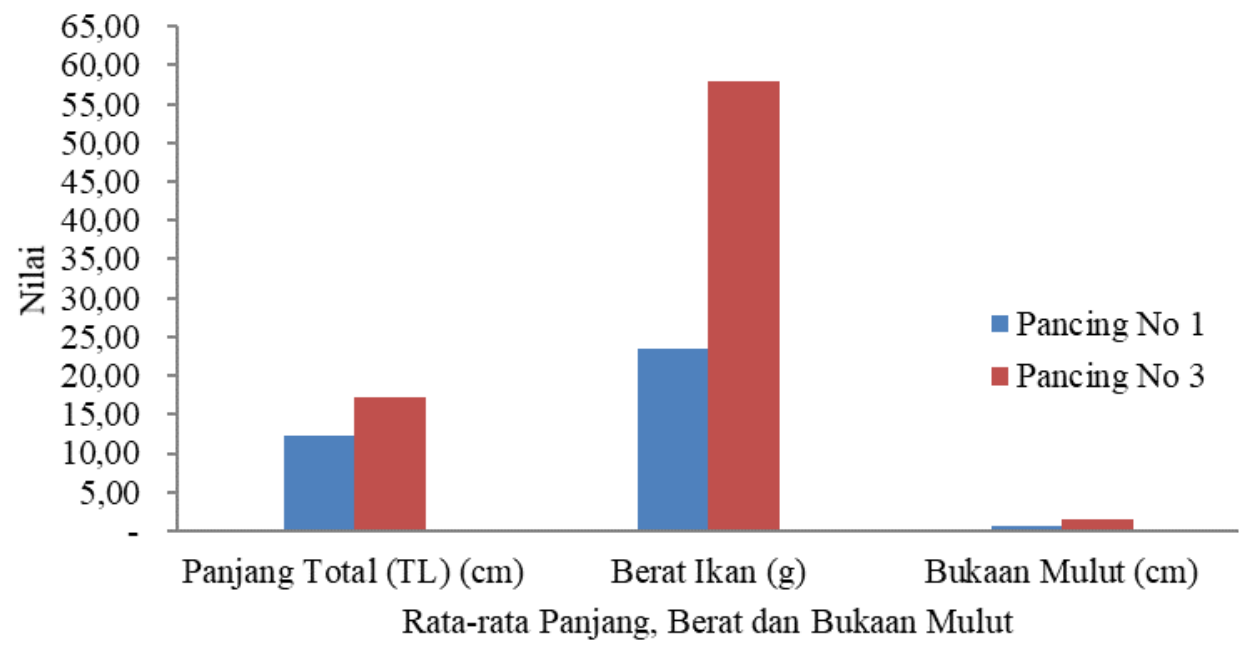

Gambar 5. Nilai Rata-Rata Panjang Total (TL), Berat (g) dan Bukaan Mulut (cm) Ikan yang Tertangkap 
Gambar 5 dapat dijelaskan bahwa rata-rata panjang total (TL) ikan yang tertangkap dengan mata pancing no. 1 adalah $12,32 \mathrm{~cm}$, dengan rataan berat ikan yang tertangkap 23,48 g dan bukaan mulut sebesar $0,59 \mathrm{~cm}$. Sedangkan pada mata pancing no. 3 rataan panjang total (TL) ikan yang tertangkap sebesar 17,20 cm dengan rataan berat ikan $58 \mathrm{~g}$ dan besar bukaan mulut sebesar $1,53 \mathrm{~cm}$. Hal ini menunjukan bahwa semakin besar ukuran mata pancing semakin panjang ukuran panjang total (TL), semakin berat ukuran berat ikan (g) dan semakin lebar bukaan mulut $(\mathrm{cm})$ ikan yang tertangkap. Demikian pula hasil penelitian Rahmat (2007) bahwa perbedaan ukuran mata pancing berpengaruh terhadap berat maupun jumlah dari tiap jenis tangkapan, yang diduga dipengaruhi faktor perbedaan fisik dari tiap ukuran mata pancing. Hasil penelitian Kurnia et al., (2015), juga menunjukan bukaan mulut ikan yang besar banyak tertangkap dengan mata pancing yang besar (no. 8 dan 10), bukaan mulut kecil banyak tertangkap dengan ukuran mata pancing nomor kecil (no. 10 dan 12).

Adapun jenis ikan yang memiliki ukuran terpanjang tertangkap pada mata pancing no. 1

\section{Sebaran Panjang Ikan}

Berdasarkan hasil penelitian didapatkan sebaran panjang total (Total Lenght) ikan yang tertangkap pancing di sungai nilo selama 12 kali percobaan adalah berkisar antara $8 \mathrm{~cm}$ sampai $19 \mathrm{~cm}$. Ukuran mata pancing yang berbeda menangkap ikan dengan kisaran yang berbeda. pada mata pancing no.1 menangkap ikan dengan panjang total $8-18 \mathrm{~cm}$ sedangkan pada yaitu ikan baung (Hemibagrus nemurus), dengan ukuran panjang total (TL) sebesar $18 \mathrm{~cm}$ dan ikan yang paling berat adalah ikan seluang (Rasbora elegans) yaitu seberat $60 \mathrm{~g}$, dan merupakan ikan dengan bukaan mulut yang paling besar pada mata pancing no. 1 yaitu $1,143 \mathrm{~cm}$. Pada mata pancing no. 3 jenis ikan yang paling panjang tertangkap juga ikan baung (Hemibagrus nemurus) dengan ukuran panjang total (TL) sebesar 19 $\mathrm{cm}$, yang juga merupakan ikan yang paling berat yaitu seberat $70 \mathrm{~g}$, sedangkan ikan yang tertangkap dengan bukaan mulut yang paling besar pada mata pancing no. 3 adalah ikan semah Tor tambra yaitu sebesar 2,083 cm. Berdasarkan jenis ikan yang tertangkap, jenis ikan yang mempunyai badan yang panjang belum tentu berat dan belum tentu mempunyai bukaan mulut yang lebar. Hal ini selaras dengan pendapat Amirulloh et al., (2014), yang menyatakan bahwa ikan yang memiliki ukuran yang panjang tidak selalu memiliki bentuk mulut yang besar sehingga ikan dengan bentuk mulut yang relatif kecil namun panjang masih dapat tertangkap pada mata pancing yang ukuranya lebih kecil.

mata pancing no.3 menangkap ikan dengan kisaran $16-19 \mathrm{~cm}$ dengan banyak ikan yang tertangkap berbedabeda. Syafrialdi et al., (2020) melaporkan bahwa ukuran ikan yang tertangkap dapat disebabkan oleh ukuran sungai dan kategori kelamin. Untuk lebih jelasnya sebaran panjang ikan yang tertangkap pada pancing di sungai nilo dapat dilihat pada (Gambar 6). 


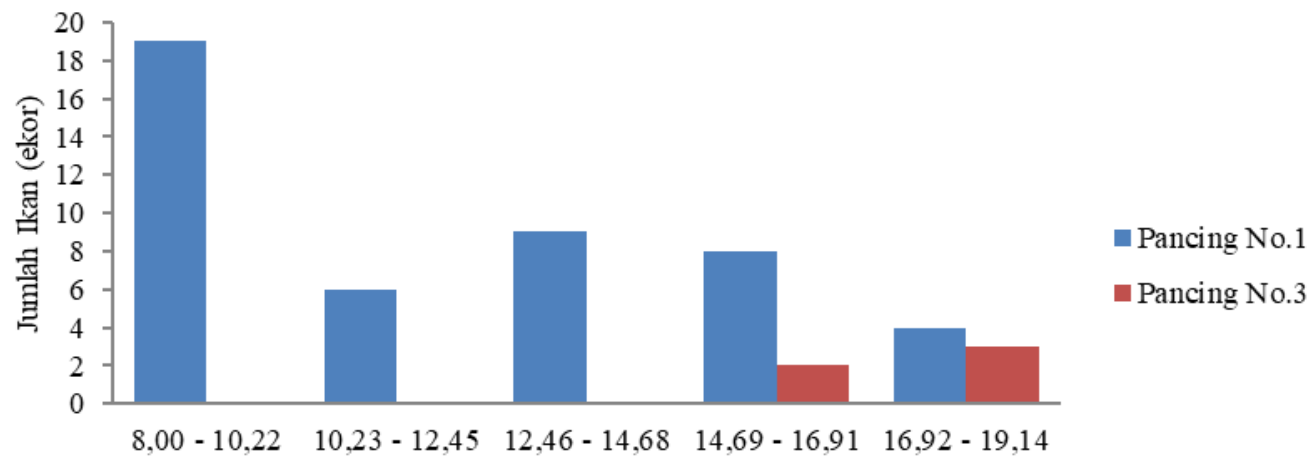

Kelas Panjang Ikan (cm)

Gambar 6. Sebaran Panjang Ikan yang Tertangkap Pada Alat Tangkap Pancing

Gambar 6 menunjukkan bahwa hasil tangkapan pancing di sungai nilo yang paling panjang berkisar antara 16,92-19,14 cm yang tertangkap pada pada mata pancing no. 1 dan no. 3 , dengan rincian pada mata pancing no. 1 ikan tertangkap sebanyak 4 ekor, sedangkan pada mata pancing no. 3 , ikan yang paling panjang tertangkap sebanyak 3. Ikan baung (Hemibagrus nemurus) merupakan yang paling panjang tertangkap dan paling dominan, baik pada ukuran mata pancing no. 1 maupun no. 3. Sebaran ikan yang paling terkecil tertangkap dengan kisaran panjang antara 8-10,22 cm yang hanya tertangkap pada mata pancing no. 1 yaitu sebanyak 19 ekor yang didominasi oleh ikan cato (Barbodes lateristriga) dan ikan seluang (Rasbora elegans) yang masing-masing sebanyak 9 ekor.

Gambar 6 juga menunjukan bahwa selama penelitian pada pancing no. 1 populasi sebaran panjang ikan yang tertangkap didominasi ikan berukuran sedang yaitu ikan cato (Barbodes lateristriga) dan ikan seluang (Rasbora elegans). Hal ini selaras dengan penelitian Suryani et al., (2018) yang menyatakan bahwa ikan seluang hasil tangkapan di hilir sungai sekadau memiliki panjang tubuh berkisar $2-16 \mathrm{~cm}$, sebaran panjang ikan menggambarkan kelompok umur ekologis yaitu kecil memiliki ukuran $2-6 \mathrm{~cm}$ ditemukan sebanyak 131 individu, ukuran sedang 7 - $11 \mathrm{~cm}$ ditemukan sebanyak 78 individu, sedangkan ikan seluang berukuran besar (dewasa) dengan kisaran $12-16 \mathrm{~cm}$ ditemukan paling sedikit berjumlah 4 individu.

Dominannya populasi ikan seluang maupun ikan cato yang tertangkap dengan kisaran panjang berukuran sedang dan muda dalam jumlah yang besar diduga karena aspek biologis yang belum waktunya untuk memijah dan matang gonad. Menurut Atetiningsih dan Windarti (2004) bahwa perkembangan gonad ikan seluang yang ditangkap selama musim penghujan (di bulan Oktober - Desember) berada dalam keadaan pematangan gamet dan memijah atau melepas gamet. Ballesteros et al., (2009) menambahkan bahwa di wilayah tropis sebagian besar ikan memijah pada saat musim penghujan. Pusey et al., (2002), Torres-Mejia et al., (2008), Alkins Koo (2000) juga menjelaskan bahwa hanya sedikit yang memijah pada saat musim kemarau atau sepanjang 
tahun. Lebih lanjut Ballesteros et al., (2009) menjelaskan bahwa tingkah laku pemijahan secara musiman tersebut dipengaruhi beberapa faktor

\section{Estimasi Selektivitas Pancing}

Analisis selektivitas alat tangkap pancing dilakukan dengan menggunakan metode Sparre dan Venema (1999) yaitu menggunakan 2 ukuran mata pancing yang berbeda. Dari hasil perhitungan terhadap logaritma rasio untuk masing-masing kelompok panjang yang saling tumpang tindih diperoleh interval kelas (Y) sebesar 2,22 dengan panjang total (TL) minimum adalah $8 \mathrm{~cm}$ dan maksimum $19 \mathrm{~cm}$ sehingga diperoleh tabel distribusi frekuensi panjang total (TL) ikan yang tertangkap. Untuk lebih jelasnya dapat dilihat pada (Tabel 2).

Tabel 2 menunjukan bahwa panjang ikan yang tertangkap bervariasi antara $8 \mathrm{~cm}$ hingga 19,14 $\mathrm{cm}$. Sedangkan mata pancing yang seperti ketersediaan daerah pengasuhan, ketersediaan makanan, suhu dan siklus hidrologi.

digunakan dengan ukuran Gap 0,406 $\mathrm{cm}$ dan $0,508 \mathrm{~cm}$. Hasil perhitungan dengan menggunakan persamaan selektivitas terhadap hasil tangkapan pancing no. 1 dan no. 3, didapat intercep $a=-9,170$ dan nilai slope $b$ $=0,493$. Nilai-nilai tersebut kemudian digunakan untuk menghitung nilai factor selection $\left(\mathrm{S}_{\mathrm{F}}\right)$, panjang maksimum-optimum length dan standar deviasi (S). Nilai faktor seleksi $\left(S_{\mathrm{F}}\right)$ didapat sebesar 40,731 dan kisaran panjang optimum ikan yang tertangkap mata pancing no. 1 (Lma) bernilai $16,537 \mathrm{~cm}$ dan kisaran panjang optimum ikan yang tertangkap mata pancing no.3 (Lmb) sebesar 20,691 cm, dengan nilai standar deviasi (S) didapat sebesar 2,904 .

Tabel 2. Distribusi Frekuensi Panjang Total (TL) Ikan yang Tertangkap Mata Pancing No. 1 dan No. 3 di Sungai Nilo

\begin{tabular}{|c|c|c|c|c|c|}
\hline \multirow{2}{*}{\multicolumn{2}{|c|}{ Panjang Kelas }} & \multirow{2}{*}{$\begin{array}{l}\text { Nilai Tengah } \\
\qquad(\mathrm{X}=\mathrm{L})\end{array}$} & \multicolumn{2}{|c|}{ Frekuensi (Ekor) } & \multirow{2}{*}{$\begin{array}{c}\operatorname{Ln}(\mathrm{B} / \mathrm{A}) \\
\mathrm{Y}\end{array}$} \\
\hline & & & Pancing No.1 & Pancing No.3 & \\
\hline 8,00 & 10,22 & 9,11 & 19 & 0 & - \\
\hline 10,23 & $-\quad 12,45$ & 11,34 & 6 & 0 & - \\
\hline 12,46 & - $\quad 14,68$ & 13,57 & 9 & 0 & - \\
\hline 14,69 & - $\quad 16,91$ & 15,80 & 8 & 2 & $-1,39$ \\
\hline 16,92 & $-\quad 19,14$ & 18,03 & 4 & 3 & $-0,29$ \\
\hline \multicolumn{3}{|c|}{ Jumla } & 46 & 5 & $-0,29$ \\
\hline
\end{tabular}

Sumber : Hasil Penelitian, 2020

Nilai maksimum-optimum length $(\mathrm{Lm})$ dan nilai standar deviasi (S) kemudian disubstitusikan ke dalam persamaa selektivitas, sehingga diperoleh persamaaan kurva selektivitas

1. Mata pancing nomor 1

$$
\mathrm{S}_{\mathrm{a}}(\mathrm{L})=\exp \left[-\frac{(\mathrm{L}-16,537)^{2}}{2 \times(2,904)^{2}}\right]
$$

2. Mata pancing nomor 3

$$
\mathrm{S}_{\mathrm{b}}(\mathrm{L})=\exp \left[-\frac{(\mathrm{L}-20,691)^{2}}{2 \times(2,904)^{2}}\right]
$$


Persamaan seletivitas ukuran mata pancing tersebut digunakan untuk menentukan selektivitas hasil tangkapan pada masing-masing ukuran spesies. Kurva selektivitas berfungsi untuk mengetahui peluang tertangkapnya ikan pada panjang tertentu.

Kurva selektivitas pada (Gambar 7) menunjukkan bahwa alat tangkap pancing dengan ukuran mata pancing no. $1(0,406 \mathrm{~cm})$ memiliki selektivitas optimal $(\mathrm{SaL}=1)$ pada ikan dengan panjang $16,537 \mathrm{~cm}$. Ikan yang tertangkap mendekati panjang optimal pada mata pancing no. 1 yaitu antara $14 \mathrm{~cm}-18 \mathrm{~cm}$ yang tertangkap sebanyak 17 ekor yaitu ikan anak batu 1 ekor, baung 5 ekor, cato 1 ekor, kabarau 1 ekor, kapiat 2 ekor, seluang 4 ekor, semalih 1 ekor dan ikan semurut 2 ekor. Pada mata pancing no. 1, ikan yang memiliki ukuran jauh diatas nilai optimal maka ikan tidak akan memakan umpan pancing tersebut karena bukaan mulut yang lebar.

Sedangkan pada mata pancing no. $3(0,508 \mathrm{~cm})$ memiliki selektivitas optimal $(\mathrm{SbL}=1)$ pada ikan dengan panjang 20,691 cm. Tetapi belum ada hasil tangkapan ikan di sungai nilo dengan panjang optimal tersebut, dan semua ikan yang tertangkap pada pancing no. 3 yaitu sebanyak 5 ekor ikan merupakan ikan yang tertangkap dengan panjang total berkisar antara $16 \mathrm{~cm}$ sampai $19 \mathrm{~cm}$ dan ikan yang memiliki panjang jauh di bawah nilai optimal tidak tertahan karena bukaan mulut ikan yang terlalu kecil. Menurut Sutanto (2005) pembatasan ukuran minimum mata pancing ikan yang akan tertangkap besar ukuran mulutnya dari mata pancing, sehingga ikan dengan mulut lebih kecil akan lolos dari penangkapan.
Hutubessy et al., (2015) menambahkan bahwa bentuk dan ukuran mulut ikan merupakan faktor utama ikan dapat terkait pada pancing. Berdasarkan hal tersebut dapat dikatakan bahwa ukuran mata pancing no. 3 lebih selektif dalam menangkap ukuran yang layak tangkap seperti ikan baung, ikan semah, ikan cato dan semalih yang mempunyai panjang total $16-19 \mathrm{~cm}$ dengan nilai $(\mathrm{SbL}=1)$ dengan panjang optimum $20,691 \mathrm{~cm}$.

Ikan kecil hanya ditangkap dengan ukuran mata pancing yang kecil (no.1) tetapi tidak akan ditangkap pada mata pancing yang berukuran besar (no. 3) karena mereka mempunyai bukaan mulut yang kecil dan tidak dapat terkait mata pancing sehingga hasil tangkapan mata pancing no. 3 ini probalitasnya nol. Sedikitnya hasil tangkapan ikan pada mata pancing no.3 bisa disebabkan daerah tangkapannya yang sempit, pasca pemijahan dan dominasi gerombolan ikan kecil yang mencari makan. Ikan dengan ukuran lebih besar akan memiliki probabilitas lebih tinggi ke ukuran tertentu, kemudian pada titik tertentu, ukuran ikan akan turun lagi karena ikan terlalu besar hanya memakan umpan dan mampu meloloskan diri dengan kekuatannya. Sedangkan ikan kecil tidak mampu meloloskan diri dari mata pancing yang ukuran kecil karena mereka bukaan mulutnya yang kecil. Sebaliknya ikan kecil mampu meloloskan diri dari mata pancing ukuran besar sehingga probabilitasnya nol, ikan dengan ukuran lebih besar akan memiliki probabilitas lebih tinggi. 


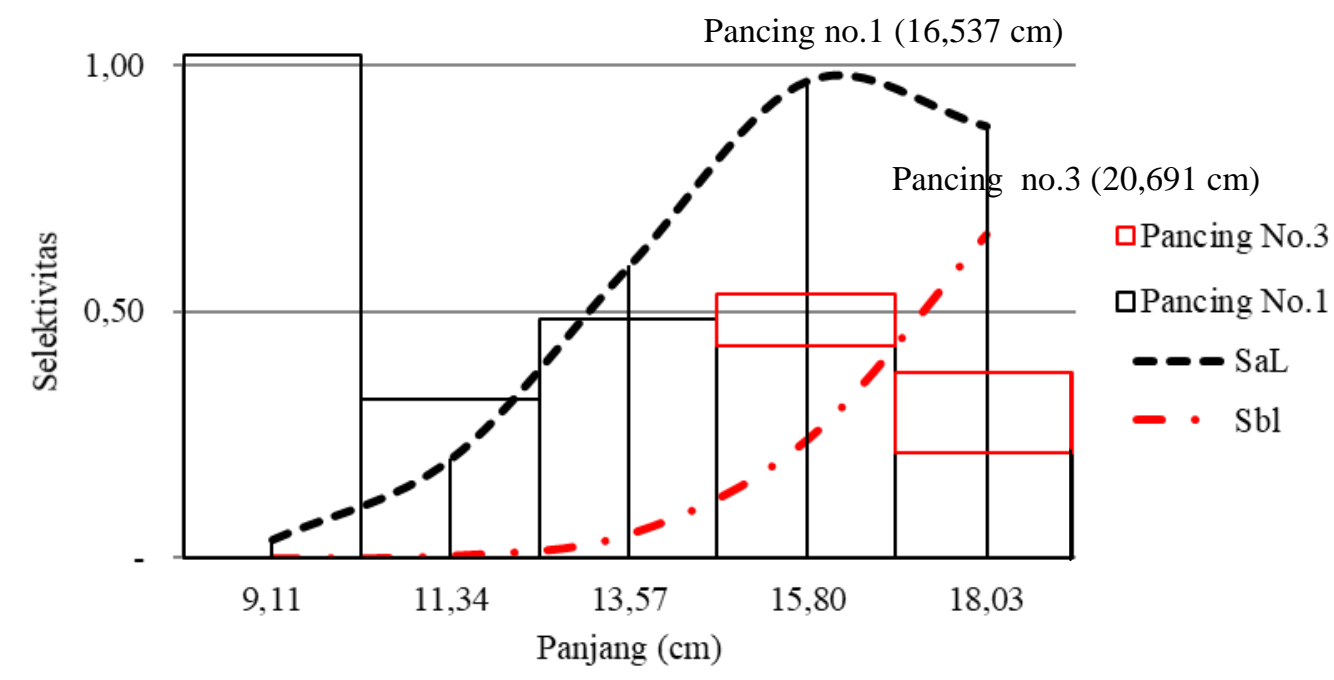

Gambar 7. Kurva Selektivitas Alat Tangkap Pancing Terhadap Hasil Tangkapan di Perairan Sungai Nilo

Kurva selektivitas pancing yang naik dari kiri kemudian berhenti pada satu titik dan kemudian ada kemiringan sedikit ke bawah di sebelah kanan prakiraan kurva seleksi menjadi model yang beragam, dan dapat berfluktuasi di antara spesies atau ukuran tergantung pada model yang dipilih untuk menyesuaikan kurva (Balasubramanian et al., 2016).

Bentuk kurva selektivitas berlaku untuk alat tangkap ukuran dan

\section{KESIMPULAN DAN SARAN}

\section{Kesimpulan}

Berdasarkan hasil penelitian dapat disimpulkan bahwa pancing yang dioperasikan di sungai nilo memiliki estimasi nilai selektivitas terhadap ikan ukuran mata pancing no. 1 pada panjang $16,537 \mathrm{~cm}$ dan ukuran mata pancing no. 3 pada panjang 20,691 cm. Panjang ikan hasil tangkapan yang memiliki panjang terluar di bawah dan diatas nilai perkiraan selektivitas kemungkinan tidak akan memakan jenis ikan tertentu, oleh karena itu, jika salah satu dari dua hal berubah, kurva juga akan bergeser (Spare \& Venema, 1999). Márquez-Fariasetal (2005), Govender dan Al-Qufi (2019) dan Kholis et al., (2020) menyatakan bahwa faktor-faktor yang dapat mempengaruhi pergerakan kurva selektivitas, seperti ekstensibilitas dan elastisitas yang rendah, jenis kelamin, kematangan gonad, jumlah makanan di usus, dan lingkungan (oseanografi).

umpan karena size ukuran mata pancing lebih besar dan lebih kecil dari bukaan mulut ikan.

\section{Saran}

Untuk menjaga sumberdaya perikanan di sungai nilo maka disarankan untuk tidak menggunakan mata pancing nomor 1 pada bulan pasca pemijahan, karena ukuran ikan yang masih kecil. 


\section{DAFTAR PUSTAKA}

Alkins-Koo, M. 2000. Reproductive timing of fishes in a tropical intermittent stream. Environmental biology of fishes 57(1): 49-66.

Amirulloh, R.P., Pramonowibowo dan A.N. Bambang. 2014. Perbedaan Ukuran Mata Pancing Alat Tangkap rawai Terhadap Hasil Tangkapan Yang Di Tangkap Di Perairan Srau Kabupaten Pacitan. Journal of Fisheries Resources Utilization Management and Technology Volume 3, Nomor 2, Tahun 2014.

Atetiningsing, S, dan Windarti, 2004, Perkembangan Gonad Ikan Pantau (Rasbora triliineata) yang ditangkap di Danau Lubuk Siam, Provinsi Riau, Ilmu Perairan Vol 2, No. 2, hal. 48 - 53

Ayodhyoa AU. 1981. Metode Penangkapan Ikan. Bogor : Yayasan Dewi Sri. Bogor.

Badan Lingkungan Hidup Daerah. 2015. Buku Data Status Lingkungan Hidup Daerah Provinsi Jambi Tahun 2014. Badan Lingkungan Hidup Daerah (BLHD) Provinsi Jambi. Jambi

Balasubramanian, A., Meenakumari, B., Pravin, P., Dhanapal, K., Boopendranath, M. R., \& Erzini, K. (2016). Estimation of gillnet and hook selectivity for Carangoides fulvoguttatus (Forsskal, 1775) captured off Kanyakumari Coast of India. Http://krishi.icar.gov.in/jspui/ handle/123456789/20353
Ballesteros, T. M; Torres-Mejia,M\& Ramírez-PinillaM. P. 2009. How does diet influence the reproductive seasonality of tropical freshwater fish? A case study of a characin in a tropical mountain river. Neotropical Ichthyology. 7 (4): 693-700

Govender, A., \& Al-Oufi, H. (2019). Gillnet selectivity of the Indian oil sardine Sardinella longiceps fished in the Sea of Oman. Journal of Agricultural and Marine Sciences, 24, 1923.

Http://dx.doi.org/10.24200/ja ms.vol24iss 0pp19-23

Hutubessy, B.G., J.W. Mosse dan A. Syahailatua. 2015. Estimasi Selektifitas Pancing Tonda Ikan Demersal. Jurnal "Amanisal" PSP FPIK Unpatti-Ambon Vol. 4. No. 1.

Jeksen, M., Syafrialdi dan Djunaidi. 2018. Pengaruh Hasil Tangkapan Alat Tangkap Bubu Dasar dengan Menggunakan Umpan yang Berbeda di Sungai Tembesi Kabupaten Merangin Provinsi Jambi. SEMAH : Journal Pengelolaan Sumberdaya Perairan. Vol. 3 No. 2. Diunduh Juli 2020.

Kholis, M. N., Martasuganda, S., Amrullah, M. Y., \& Jaliadi. 2020. Estimation of gillnet selectivity for Tor tambra captured in Lirik River, Merangin Regency, Jambi Province. Tomini Journal of Aquatic Science, 1(1), 29-36

Kurnia, M., Sudirman., dan M. Yusuf. 2015. Pengaruh Perbedaan Ukuran Mata Pancing Terhadap Hasil Tangkapan 
Pancing Ulur di Perairan Pulau Sabutung Pangkep. Marine Fisheries. Vol. 6, No. 1.

Márquez-Farias, J. F., CorroEspinosa, D., Castillo-Géniz, J. L. 2005. Observations on the biology of the Pacific sharpnose shark (Rhizoprionodon longurio, Jordan and Gilbert, 1882), captured in Southern Sinaloa, México. Journal of Northwest Fishery Science, 35, 107-114. Https://doi.org/10.2960/J.v35. m506

Nugroho P. 2002. Pengaruh Perbedaan Ukuran Mata Pancing Terhadap Hasil Tangkapan Pancing Tonda di Perairan Pelabuhanratu Sukabumi Jawa Barat. (Skripsi). Bogor (ID): Institut Pertanian Bogor.

Pusey, B. J;Arthington,A. H; Close, P. G\& Bird, J. R. 2002. Larval fishes in rainforest streams: recruitment and microhabitat use. Proceedings of the Royal Society of Queensland. 110: 27-46

Sastrapradja, S., A. Budiman, M. Djajasasmita, dan C.S. Kaswadji. 1981. Ikan Hias. LBN - LIPI. Bogor

Siagian, C. 2009. Keanekaragaman dan Kelimpahan Ikan Serta Keterkaitannya Dengan Kualitas Perairan di Danau Toba Balige. Tesis. Universitas Sumatera Utara. Medan

Sparre, P \& Venema, S.C. 1999. Introduksi Pengkajian Stok ikan Tropis. Terjemahan Pusat Penelitian dan Pengembangan Perikanan, Badan Penelitian dan Pengembangan Pertanian. Puslitbangkan. Jakarta.
Suryani, F.Y., T.R. Setyawati dan A.H. Yanti. 2018. Struktur Populasi Ikan Seluang (Rasbora argyrotaenia) di Hilir Sungai Sekadau Kecamatan Sekadau Hilir Kabupaten Sekadau. Protobiont (2019) Vol. 8 (2) : $74-81$

Sutanto, H.A. 2005. Analisis Efisiensi Alat Tangkap Perikanan Gillnet Dan Cantrang (Studi di Kabupaten Pemalang Jawa Tengah). Tesis.Program Pasca Sarjana Universitas Diponegoro. Semarang.

Syafrialdi., Dahelmi., Roesma, D.I and Syandri, H. 2020. LengthWeight Relationship and Condition Factor of Two-Spot Catfish (Mystus nigriceps [Valenciennes, 1840]) ( Pisces, Bagridae), from Kampar Kanan River and Kampar Kiri River in Indonesia. Pakistan Journal of Biology Sciences. 23 (12), 1636-1642.

Warsa, A., \& Astuti, L. P. (2019). Ukuran Pertama Kali Matang Gonad Dan Selektivitas Jaring Insang Ikan Nila (Oreochromis niloticus) di Waduk Jatiluhur, Jawa Barat. Berita Biologi, 18(3), 283293.

Yusuf, H.N. 2016. Karakteristik Teknis Pukat Cincin, Pengaruhnya Terhadap Hasil Tangkapan di Pacitan Jawa Timur. Tesis. Sekolah Pascasarjana Institut Pertanian Bogor. Bogor. 